\title{
ASPECTOS MORFOLÓGICOS DA GERMINAÇÃO E DO DESENVOLVIMENTO PLANTULAR EM Euterpe precatoria MART. (AÇAÍ-DO-AMAZONAS) ${ }^{1}$
}

\author{
Madalena Otaviano AGUIAR ${ }^{2}$, Maria Sílvia de MENDONCA ${ }^{3}$
}

\begin{abstract}
RESUMO - Euterpe precatoria Mart. é uma palmeira amplamente distribuida na bacia Amazônica, em terra firme e em solos de várzea. Dos frutos obtêm-se o "vinho do açai" e do ápice caulinar o palmito, que fazem desta palmeira um importante recurso alimentar. Neste trabalho é feita a descrição morfológica do desenvolvimento plantular durante a germinação da semente, contribuindo para o entendimento do processo e fornecendo subsídios para produção de mudas. A germinação é do tipo adjacente ligulada. A raiz primária emerge primeiro e desenvolve-se mais rapidamente que a plúmula; posteriormente, aparecem as raizes secundárias e terciárias.
\end{abstract}

Palavras-chaves: Euterpe precatoria, palmeira, morfologia, germinação

Morphological Aspects and Development of the Seedling of Euterpe precatoria Mart. Açaido-Amazonas)

ABSTRACT - Euterpe precatoria Mart. is a common palm tree in the Amazon basin, in the floodplains and in uplands. The fruits are used for juice and palm heart is obtained from the shoot apex, so that it is an important food source. In this paper a morphological description of the developing seedling during the germination process is presented as a contribution for the understanding of this process and as a basis for the development of more efficient techniques of planting material production. The germination is of the adjacent ligular type. The radicle emerges first and grows faster than the plumule, with secoundary and tertiary roots appearing later on.

Key-words: Euterpe precatoria, palm, morphology, germination.

Euterpe precatoria é amplamente distribuida por toda a bacia Amazônica, de Norte a Sul (Kahn \& Granville, 1992). Cresce dentro de uma variedade de habitats e na região Amazônica é comum ao longo das margens dos rios em floresta periodicamente inundada em baixas elevações (Henderson et al., 1995). É vulgarmente conhecida como açaí-deterra-firme, açaí-solitário, açaí-doAmazonas, açaí-do-mato, palmito mole e juçara. Tem potencial para manejo econômico, visto que dela podem ser extraídos o suco do fruto ("vinho de açai") e o palmito.

A morfologia da semente durante a germinação tem sido estudada, para ampliar o conhecimento sobre determinadas espécies ou agrupamento sistemático e, segundo Pinheiro \& Araújo Neto (1987), é importante para o entendimento completo do processo germinativo e básico para o desenvolvimento de técnicas eficientes de produção de mudas. Neste sentido, informações sobre a morfologia do desenvolvimento plantular de Euterpe precatoria é necessário, visto que sua propagação dá-se via semente.

'Parte da Dissertação de Mestrado apresentada ao INPA/UA pela primeira autora.

${ }^{2}$ MSc. em Botânica, R.15, Qd.P, 300, Conj. Colina Aleixo, 69083-570 (moaguiar@uol.com.br).

${ }^{3}$ Profa. Titular - Universidade do Amazonas, FCA/DCFDA. 
As sementes foram procedentes das áreas do mini-campus da Universidade do Amazonas e da Rodovia AM-010 (km 09 e 13). De cada área foram coletados frutos maduros de três matrizes, os quais foram misturados; separou-se aleatoriamente uma amostra de 70 frutos. Para obtenção das sementes e para acelerar o processo germinativo, os frutos foram tratados imergindo-os em água à temperatura de $40^{\circ} \mathrm{C}$ por 20 minutos (Nogueira et al., 1995); em seguida, retirou-se manualmente a polpa e a parte fibrosa.

A semeadura foi feita a $2 \mathrm{~cm}$ de profundidade com o opérculo na posição horizontal e a rafe voltada para baixo, procedimento baseado nas observações de Belin-Depoux \& Queiroz (1971). Como substrato, utilizou-se pó de serragem curtida, mantida sempre úmida, em ambiente de viveiro, coberto com tela sombrite preta, com $50 \%$ de luminosidade (Pinheiro, 1986). Para o acompanhamento das fases da germinação foi estabelecido à retirada de 10 sementes a cada intervalo de 10 dias, a contar do primeiro dia de semeadura até o $70^{\circ}$ dia. As avaliações morfológicas foram feitas com material fresco e, quando necessário, utilizou-se lupa binocular. As fotomicrografias foram feitas em fotomicroscópio Axioskop, com câmara MC-80.

No presente trabalho, considerou-se como germinação à fase que se inicia com o aparecimento do botão germinativo (Fig. 1A) e termina com a protrusão da primeira bainha
(Fig. 1D). Usou-se a terminologia de Belin \& Queiroz (1988) nas descrições.

$\mathrm{O}$ inicio do desenvolvimento plantular (germinação), que ocorreu no período de 10 a 20 dias após a semeadura, foi marcado pelo aparecimento de uma estrutura de aspecto cônico, de cor amarela esbranquiçado que corresponde ao pecíolo cotiledonar. Em Euterpe edulis, Belin \& Queiroz (1988) a chamaram de botão germinativo ou botão cotiledonar. Esta estrutura, no momento da protrusão, pressiona o tegumento que se destaca em forma de disco (opérculo) (Fig. 1A).

A forma do botão foi logo modificada nos primeiros 30 dias após a semeadura, com o surgimento da raiz primária, seguida de uma protuberância pontiaguda, com extremidade vermelha púrpura, formada pela plúmula que se desenvolve lateralmente no botão, deslocando-se em direção contrária a raiz (geotropismo negativo) (Fig. 1B).

O desenvolvimento da raiz primária é muito mais rápido do que o da plúmula. Observou-se que quando o primeiro primórdio foliar apareceu externamente, a raiz primária já mediu mais de $3 \mathrm{~cm}$ de comprimento (Fig. 1C). Esta mesma observação foi feita por Hartley (1977) para Elaeis guineensis e por BelinDepoux \& Queiroz (1971) para Euterpe edulis.

A primeira bainha aparece à superfície do solo entre 40-45 dias após o início da germinação, e tem em média $18,4 \mathrm{~mm}$ de comprimento e 
2,2 $\mathrm{mm}$ de diâmetro. Neste momento, o sistema radicular é formado pela raiz primária, que tem em média $40,9 \mathrm{~mm}$ de comprimento e 0,85 $\mathrm{mm}$ de diâmetro, além de raizes secundárias. Estas raízes são consideradas por Corner (1966) e Tomlinson (1990) como raízes adventícias, entretanto, optou-se por denominá-las de raizes secundárias devido a sua origem no periciclo.

Dentre as raízes secundárias uma se destaca por ter maior diâmetro e emergir sempre abaixo da raiz primária (Fig. 2B), crescendo mais rapidamente, penetrando profundamente no solo, alcançando em média 19,2 cm de comprimento, no momento da expansão do eófilo.

As transformações que ocorrem no botão promovem o surgimento da lígula (Fig. 1C-D). Trata-se de uma estrutura membranosa tubular, decorrente das modificações do botão durante o processo de germinação, tornando-se evidente após a emergência radicular e caulinar, permanecendo durante a fase plantular. De acordo com Tomlinson (1961, 1990), a lígula pode estar presente ou ausente em diferentes espécies de palmeiras. Sua função não é bem esclarecida, mas ela poderia ajudar na orientação da plúmula numa posição ereta.

$$
\text { Desde o início }
$$
desenvolvimento plantular, a região distal do embrião aumenta progressivamente de tamanho, funcionando como um órgão de absorção, o haustório (Figs 2A-D). Esta região, segundo Alves \&
Demattê (1987), é tida como o verdadeiro cotilédone das palmeiras, pois tem a função de dissolver e absorver o endosperma; já a região proximal é considerada apenas como uma bainha que protege o eixo embrionário.

O peciolo cotiledonar pode se estender ou não, além da inserção da semente. Esta caracteristica é importante porque separa sistematicamente grupos de palmeiras. Tomlinson (1990) reconhece três categorias principais: eixo cotiledonar estendido com ou sem lígula (germinação do tipo remota ligular e germinação do tipo remota não ligular, respectivamente) e eixo cotiledonar não estendido, lígula geralmente presente (germinação do tipo adjacente).

Em Euterpe precatoria o alongamento do peciolo cotiledonar cessa quando o eixo embrionário emerge da semente (Fig. 2D); assim como em Euterpe edulis (BelinDepoux \& Queiroz, 1971), isto faz com que a plântula se desenvolva próximo a semente (Figs. 1 e 2). Este comportamento inclui a espécie Euterpe precatoria no grupo das palmeiras que apresentam germinação do tipo adjacente ligulada, assim como todas as demais espécies do gênero Euterpe, referenciadas por Uhl \& Dransfield (1987) e Henderson (1995).

\section{Bibliografia citada}

Alves, M.R.P.; Demattê, M.E.S.P. 1987. Palmeiras: caracteristicas botânicas $e$ 
evolução. Fundação Cargill, Campinas. $129 \mathrm{p}$.

Belin-Depoux, M.; Queiroz, M.H. 1971. Contribution à l'étude ontogénique des palmiers. Quelques aspects de la germination de Euterpe edulis Mart. Revue Générale de Botanique, 78:339-371.

Belin, M.; Queiroz, M.H. 1988. Contribuição ao estudo ontogênico das palmeiras. Alguns aspectos da germinação de Euterpe edulis Mart. In: Anais do I Encontro Nacional de Pesquisadores em Palmito, EMBRAPA-CNPF, Curitiba. p.211-213.

Corner, E.J.H. 1966. The natural history of palms. University of California Press, Los Angeles. 393p.

Hartley, C.W.S. 1977. The oil palm. 2. ed. Longman, London. 806p.

Henderson, A. 1995. The palms of the Amazon. Oxford University Press, New York. 362p.

Henderson, A; Galeano, G.; Bernal, R. 1995. Palms of the Americas. Princeton University Press, Princeton. 352p.

Kahn, F,; Granville, J. 1992. Palms in forest ecosystems of Amazonia. Springer Verlag, New York. 226p.

Nogueira, O.L.; Carvalho, C.J.R.; Müller, C.H.;
Galvão, E.U.P.; Silva, H.M; Rodrigues, J.E.L.F.; Oliveira, M.S.P.; Carvalho, J.E.U.; Rocha Neto, O.G.; Nascimento, W.M.O.; Calzavara, B.B.G. 1995. A cultura do açai. Coleção plantar, $n^{0} 26$. EMBRAPA-SPI, Brasilia, DF. 49p.

Pinheiro, C.U.B. 1986. Germinação de sementes de palmeiras: revisão bibliográfica. EMBRAPA-UEPAE, Teresina. 102p.

Pinheiro, C.U.B.; Araújo Neto, A. 1987. Germinação de sementes de palmeiras do complexo babaçu (Palmae Cocosoideae). Pesquisa em Andamento, EMAPA, São Luiz. 4p.

Tomlinson, P.B. 1961. Anatomy of the Monocotyledons. II. Palmae. Clarendon Press, Oxford. $453 \mathrm{p}$.

Tomlinson, P.B. 1990. The structural biology of palms. Clarendon Press, Oxford. 460p.

Uhl, N.W.; Dransfield, J. 1987. Genera Palmarum. Allen Press, Lawrence. 610p. 

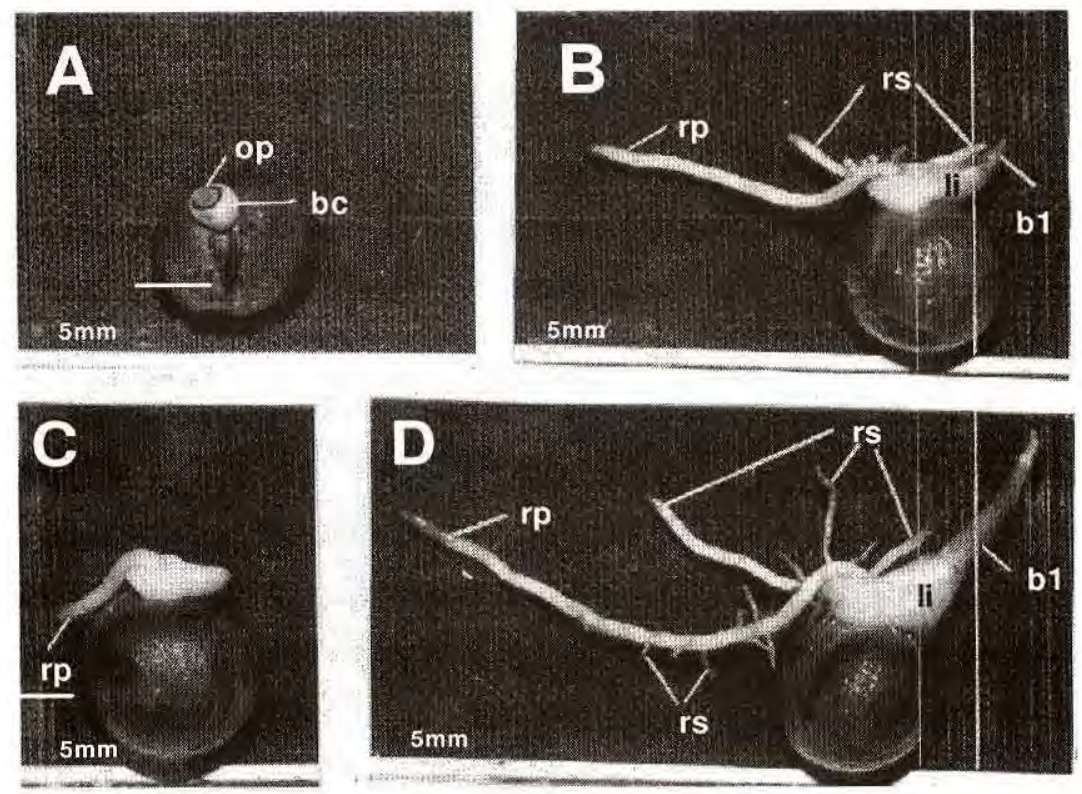

Figura 1. Fases da germinação da semente de Euterpe precatoria (A-D). b1, primeira bainha; bc, botão cotiledonar; li, ligula; op, opérculo; rp, raiz primária; rs, raizes secundárias; rt, raizes terciárias.
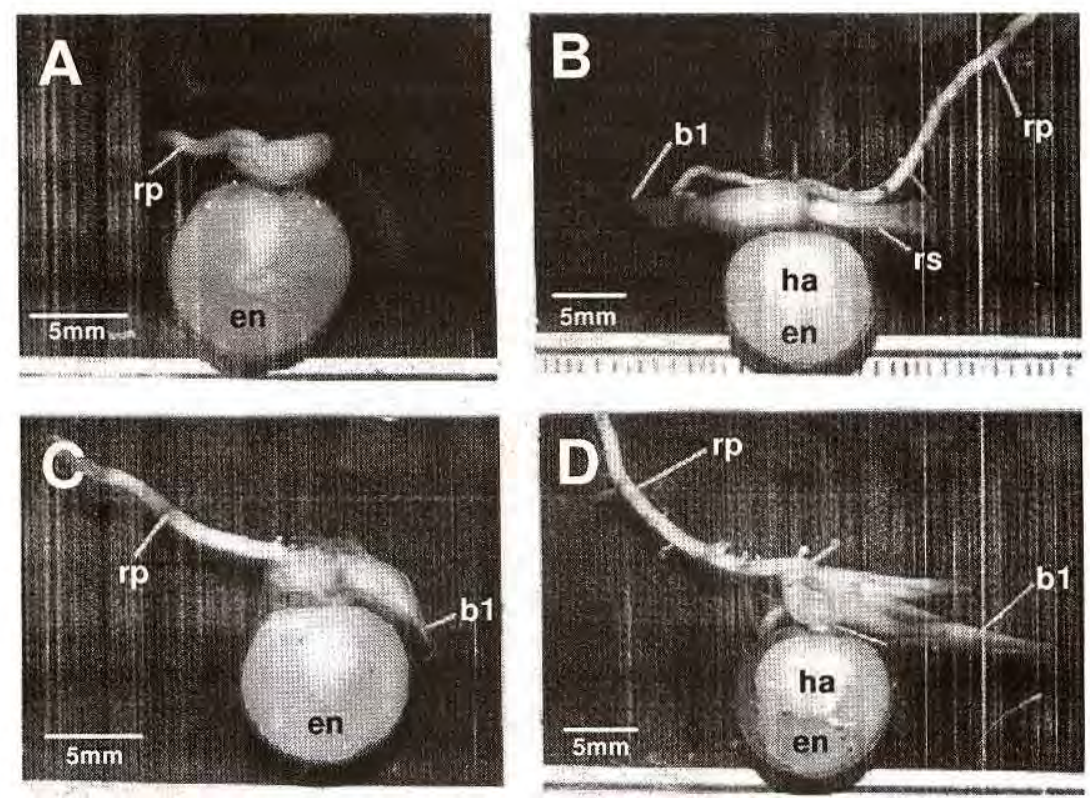

Figura 2. Fases da germinação em secção longitudinal da semente de Euterpe precatoria (A-D). b1, primeira bainha; en, endosperma; ha, haustório; pe, peciolo cotiledonar; rp, raiz primária; rs, raiz secundária. 